\title{
Unexpected high overwintering survival rate of the cavity-dwelling ant Temnothorax crassispinus (Hymenoptera: Formicidae)
}

\author{
Slawomir Mitrus
}

Mitrus, S. 2015: Unexpected high overwintering survival rate of the cavitydwelling ant Temnothorax crassispinus (Hymenoptera: Formicidae). - Entomol. Fennica 26: 194-200.

The mortality rate of many invertebrates is high during winter. The survival rate of the ant Temnothorax crassispinus, which overwinters aboveground, was investigated. Unlike previous studies, this one showed a high survival rate during winter. In the field experiment, the number of workers at the end of the experiment amounted to $86-120 \%$ of the initial numbers, and 73 out of 74 queens survived. The high survival rate was most likely a result of the favourable weather conditions. In the laboratory experiment, none of the workers exposed to $-24{ }^{\circ} \mathrm{C}$ survived, while the survival rate of workers kept in $5{ }^{\circ} \mathrm{C}$ was higher $(73.2 \%$ on average) than those in $0{ }^{\circ} \mathrm{C}(53.2 \%)$. The expected rise in temperatures as a consequence of climate change may result in a higher survival rate in the winter season, but also in the reduction of snow cover, which may exert the opposite effect.

S. Mitrus, Laboratory of Evolution and Animal Ecology, Department of Biosystematics, Opole University, Oleska 22, 45-052 Opole, Poland; E-mail: smitrus@uni.opole.pl

Received 9 December 2014, accepted 7 July 2015

\section{Introduction}

Mortality rate is one of the basic parameters that determine the life history of organisms (Stearns 1992). Winter mortality can be critical for animals, including invertebrates, living in the temperate zone, although the bulk of life history data is collected outside the winter season (Leather et al. 1995, Herbers \& Johnson 2007, Bradshaw \& Holzapfel 2010). Organisms use the warmer period for their growth, development and reproduction, while survival during overwintering plays an important role in determining population size in the following spring and summer (Leather et al. 1995, Bradshaw \& Holzapfel 2010).

In temperate zone, winter is a time of low food availability, and temperatures during the period typically are too low for foraging activity and brood development. Thus, before the colder period, invertebrates could migrate to escape such unfavourable conditions (Leather et al. 1995, Bale \& Hayward 2010). Species not migrating might be tolerant for low temperatures; cold tolerance often increases following the temperature-induced seasonal acclimatisation, and many invertebrates are able to produce ice nucleating agents, e.g. cryoprotectants, which function to limit freeze damage. However, many species simply spend the unfavourable period in sites where conditions are more convenient for survival, e.g. they hide underground. Such sites below the soil surface are generally warmer and ex- 
perience less variable temperature regimes (Leather et al. 1995, Bale 1996, Bale \& Hayward 2010).

Although the majority of ants living in the temperate zone spends winters underground, avoiding exposure to low temperatures, ants of the genus Temnothorax (Hymenoptera: Formicidae) can overwinter in their nests aboveground (Herbers 1989, Herbers \& Johnson 2007). In such conditions, temperature may affect their survival to a large extent. For instance, worker survival rates recorded during two subsequent seasons in separate Temnothorax curvispinosus (Mayr) ant nests were $32.5 \%$ and $45.4 \%$ on average, and queen survival rates reached $45.4 \%$ and $52.7 \%$ respectively (Herbers \& Johnson 2007). Mitrus (2013) demonstrated in Temnothorax crassispinus (Karavajev) colonies that $48.4 \%$ (median) of workers survived the 2011/12 winter in nests situated aboveground, whereas the survival rate of workers in nests placed experimentally $5 \mathrm{~cm}$ below the ground level was higher $(87.9 \%$ survived). These results were consistent with expectations. However, during another experiment performed in the 2012/13 season, T. crassispinus worker survival rates in two different (in nest chambers' volume) experimental groups in aboveground nests were $92.1 \%$ (29.3-100\%, $N=40)$ and $95.9 \%(43.8-100 \%, N=42)$ [median (min-max range, no. of colonies)] (the colonies contained $0-3$ queens), while 80 out of 88 queens (91\%) survived the winter (Mitrus unpublished data). Differences in the obtained values may be due to different temperatures in the winter season. For instance, the minimum aboveground temperature in the $2011 / 12$ and $2012 / 13$ seasons was $-13.7^{\circ} \mathrm{C}$ and $-4.8^{\circ} \mathrm{C}$, respectively (Mitrus 2013, and unpublished data), but could also be due to such factors as different snow cover thickness and duration, neither of which was analysed in the above-mentioned studies.

The ongoing process of climate change, including variation in winter season conditions, will have an impact on the survival of species and the related ecosystems. In the case of insects, which are exposed to low temperatures during winter, the anticipated increase in temperatures ensuing from global climate change should enhance their chances of survival (Bale \& Hayward 2010, Bradshaw \& Holzapfel 2010, but see also e.g. Sorvari et al. 2011, Haatanen et al. 2015), although contrary effects should be expected as a consequence of snow cover reduction (Leather $e t$ al. 1995, Bale \& Hayward 2010).

The aim of this study was to determine winter survival and the impact of snow cover on the survival of $T$. crassispinus ants overwintering in aboveground nests. In the season 2013/14 the weather conditions made it impossible to obtain an answer to the impact of snow cover, but notwithstanding the lack of snow throughout most of the period, the ant survival rate was high. This suggests that diverse conditions in the winter may cause major variations in the survival rates of overwintering ants.

\section{Materials and methods}

\subsection{Study organisms}

The cavity-dwelling ant $T$. crassispinus is present throughout Western and Central Europe and it is a species widely distributed in Poland, known mostly from sites in coniferous forests (Seifert 2007, Czechowski et al. 2012). This species is among the most widely distributed ant species and most common as small colonies, ranging from a few dozen to several hundreds of workers (Seifert 2007, Czechowski et al. 2012). Colonies of Temnothorax ants are usually monogynous (have one queen) (Heinze \& Buschinger 1988, Seifert 2007, Czechowski et al. 2012).

\subsection{Field experiment}

On 25 and 28 October 2013 near Opole, I collected 98 colonies of the ant $T$. crassispinus containing 8-398 workers (median 97, quartiles: 48142) and 0-7 queens (the mode: 1). For the field experiment I selected 72 colonies containing one queen $(N=69)$ or two queens $(N=3)$ and $13-234$ workers (median: 98, quartiles: 57-137).

I transferred the colonies to square Petri dishes $(10.2 \mathrm{~cm} \times 10.2 \mathrm{~cm} \times 1.9 \mathrm{~cm})$ with a thin plaster base and an artificial nest chamber placed on top. The nests used in this experiment were made of birch woodblock with dimensions of 7 $\mathrm{cm} \times 1.8 \mathrm{~cm} \times 1.8 \mathrm{~cm}$. Each woodblock was drilled lengthwise to form a $4 \mathrm{~mm}$ hole, which 
was tightly closed on one side with a beech plug, and partially closed by a splinter from such a plug on the other. Such nest chambers fashioned in wood pieces are willingly accepted by Temnothorax ants (Foitzik et al. 2003). The dishes were kept in a Pol-Eko ST 1 thermostatic cabinet (manufactured by POL-EKO Aparatura sp.j.) maintaining a daily cycle comprising LD 11:13 h, in a temperature of $14^{\circ} \mathrm{C}$ and $7{ }^{\circ} \mathrm{C}$, respectively.

From 4 to 21 November, when the artificial nests had already been settled by ants, the temperature was gradually decreased and the night prolonged (the final culture regime was LD 10:14 h, $6^{\circ} \mathrm{C}$ and $3{ }^{\circ} \mathrm{C}$, respectively). During that time ants were fed twice a week with frozen fruit flies Drosophila hydei Sturtevant and honey; any dead workers found were counted and removed from the Petri dishes $(0-17$ workers died in different colonies, median 1; a dead queen was found on one Petri dish). The final number of workers in the field experiment colonies was 13-220 (median: 97, quartiles: 55-132). On 25 November I closed the entrances to the artificial nests with a metal netting to prevent the ants from escaping. Subsequently, I divided the nests randomly into four groups, 18 nests in each group.

As snow cover does not remain for long near Opole, an experiment concerning the impact of snow cover on ant survival was also planned for a site near Olkusz. Winter temperatures are usually lower in this region, whilst the snow cover is thicker and persists for longer (Lorenc 2005, Kożuchowski 2011).

I laid out the nests with ants, near Opole and also near Olkusz on 27 and 28 November 2013, respectively (I did this after the first slight frosts and initial snowfalls, which took place during the night of $24 / 25$ November). The ambient temperature was about $0{ }^{\circ} \mathrm{C}$ on these days, and both study areas were lightly snow-dusted. The nests were attached to some $16 \mathrm{~cm}$ long sticks poked into the ground. Previously calibrated AZ 88128 (AZ Instrument Corp.) data loggers were placed on the ground near the nests. Then I covered the areas with a plastic net with $16 \mathrm{~mm}$ mesh fastened to the ground with plastic pegs. Subsequently, I randomly selected and marked out an experimental part (where a systematic snow removal action was planned) and a control part (no snow removal). The experimental plan included the sys- tematic clearing of snow cover from the experimental parts. However, snowfalls in the season 2013/14 were sporadic and small, with the snow only remaining for short periods, and therefore the experimental parts were only subjected to this process a couple of times. For instance, I removed snow from the experimental parts on 29 and 30 January 2014, but as soon as on 6 February the control parts were partially devoid of snow cover, with ant nests sticking out amid the scanty amount of snow.

The maximum thickness of snow cover observed in late January was $3 \mathrm{~cm}$ and $10 \mathrm{~cm}$ near Opole and Olkusz, respectively. I collected nests on 28 February 2014 (near Opole) and on 2 March (near Olkusz), transported to a laboratory and placed in a culture chamber at $3{ }^{\circ} \mathrm{C}$. The temperature was then gradually increased (to reach the daily cycle of LD $10: 14 \mathrm{~h}, 9{ }^{\circ} \mathrm{C}$ and $5{ }^{\circ} \mathrm{C}$, respectively). On 30 March 2014, I carefully opened the nests and counted live individuals.

The lowest temperature recorded during the field experiment was $-4.7^{\circ} \mathrm{C}$ near Opole and -7.8 ${ }^{\circ} \mathrm{C}$ near Olkusz. The day temperature in both regions reached over $+10^{\circ} \mathrm{C}$ during a several-day period in February (maximums recorded: +11.6 ${ }^{\circ} \mathrm{C}$ and $\left.+14.8^{\circ} \mathrm{C}\right)$.

\subsection{Laboratory experiment}

In order to determine how various overwintering temperatures and frost exposure affect survival rates, I used workers from nine colonies containing 111-394 workers and 0-4 queens (collected during the field experiment colony collection see above). Three groups of workers, 20 individuals each, were haphazardly captured from each of the colonies on 30 November 2013. I transferred these groups to a culture chamber (LD $10: 14 \mathrm{~h}, 10^{\circ} \mathrm{C}$ and $3{ }^{\circ} \mathrm{C}$, respectively) in square Petri dishes containing artificial nests. Each nest chamber was made of a $3 \mathrm{~mm}$ thick plexiglass frame sandwiched between two halves of microscope slides. A piece of cardboard providing the base for the nest was placed between the bottom microscope slide and the plexiglass form. The whole nest was coated with a piece of red, translucent filter from above. Ants were fed twice a week with frozen fruit flies Drosophila hydei and honey. There were five Petri dishes where one 
Table 1. Change (\%) in number of workers of Temnothorax crassispinus ants during overwintering experiment near Opole and near Olkusz, Poland (end of November 2013 to beginning of March 2014). From experimental part of both areas snow cover was removed, while at control parts it not done. Increase in number of workers is probably due to completion of larval development during winter. $N$ is number of colonies.

\begin{tabular}{lllll}
\hline & & Median & Min-max & Quartiles \\
\hline Opole area & & & & \\
& Experimental group $(N=18)$ & 97.8 & $88.9-103.7$ & $94.3-102.1$ \\
Olkusz area & Control group $(N=18)$ & 97.2 & $86.0-109.5$ & $93.9-100.3$ \\
& Experimental group $(N=18)$ & 96.8 & $88.9-120.0$ & $95.1-100.0$ \\
& Control group $(N=18)$ & 97.0 & $80.3-105.3$ & $93.7-100.0$ \\
\hline
\end{tabular}

worker died; hence, the groups eventually comprised 19-20 workers. After the ants had settled in the nests, the temperature was gradually reduced until it reached $0{ }^{\circ} \mathrm{C}$ on 16 December. Subsequently, I sealed the entrances to the nest chambers with cotton wool and I placed the nests in three styrofoam boxes with $6.5 \mathrm{~mm}$ thick walls, where five $4 \mathrm{~mm}$ holes were bored to enable air penetration. The boxes were then assigned to experimental groups and put in a culture chamber:

- in a constant temperature of approximately 5 ${ }^{\circ} \mathrm{C}$,

- in a constant temperature of approximately 0 ${ }^{\circ} \mathrm{C}$,

- in a constant temperature of approximately 0 ${ }^{\circ} \mathrm{C}$, except one week (13-20 January) when the cultures were transferred to a freezer with a temperature of approximately $-24{ }^{\circ} \mathrm{C}$. In that case, the styrofoam box was additionally placed in a large styrofoam box with $25 \mathrm{~mm}$ walls to ensure a gradual change of temperature, which took over ten hours.

On 3 March, the styrofoam boxes were put in a chamber in a temperature of $0{ }^{\circ} \mathrm{C}$ on $3 \mathrm{March}$, and the temperature was then gradually increased over the period from 6 to 20 March. I opened the nest chambers and counted live workers on 21 March.

\subsection{Statistical analysis}

I compared changes in the number of workers in nests from each group during the experiment. The change in the number of workers was calculated as: (number of workers at the end of experi- ment/number of workers at the beginning of experiment) $\times 100 \%$.

I used Spearman's nonparametric correlation coefficient when analysing relations between the number of workers and the survival rate, as the distributions of the number of workers in different groups were not consistent with normal distribution.

A paired-sample Student's $t$ test (comparing worker groups originated from the same colony) was used to compare survival rate of ants kept under regime $5{ }^{\circ} \mathrm{C}$ and $0{ }^{\circ} \mathrm{C}$, during the laboratory experiment.

I carried out statistical analyses using the software package Statistica, ver. 10 (StatSoft 2011). All probability values shown are two-tailed.

\section{Results}

In the field experiment, the number of workers at the end of the experiment amounted to 80.3$120.0 \%$ of the initial value (Table 1 ). In 19 nests (from all four groups) a larger number of workers was found compared with the total noted at the beginning of the experiment (by 1-7, median 2). For instance, one colony that had 35 workers at the beginning was found to contain 42 at the end of the experiment ( $=120 \%$ of the initial number). In the end of the experiment, some of the workers in the colonies had a different (lighter) colouration, typical of young workers. There were no differences in the change in the number of workers between the groups (Kruskal-Wallis test: $H_{d f=3, N=7}=0.82$, $p=0.84$ ). Out of 74 queens, 73 survived the winter. There was no correlation between the number of workers in the nest at the beginning of the experi- 


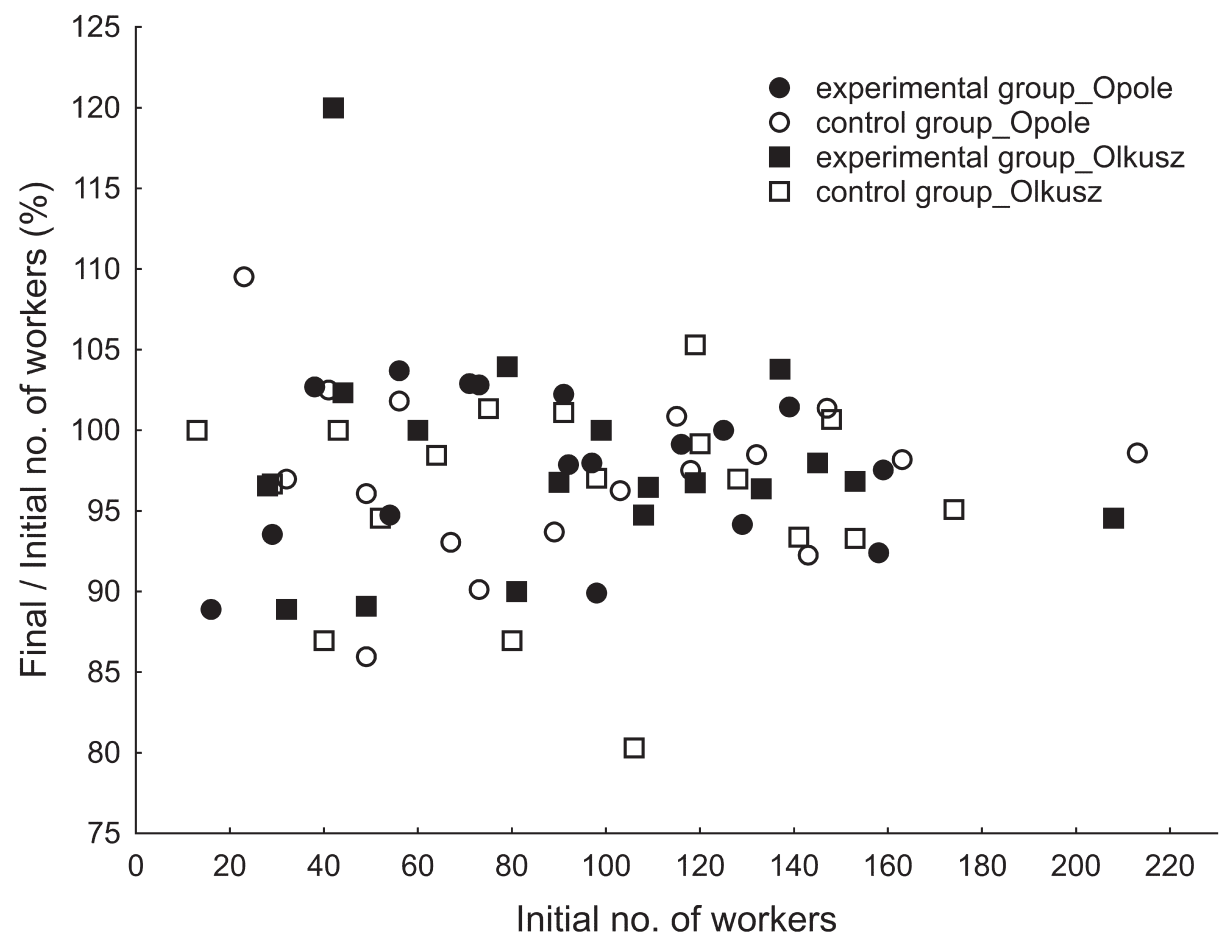

Fig. 1. Changes in number of workers of Temnothorax crassispinus ants during overwintering experiment (end of November 2013 - beginning of March 2014) relative to initial number of workers. From experimental part of both areas snow cover was removed, while at control parts it was not done. Spearman's correlation coefficient for four groups: $r_{s}=-0.13-0.003, p=0.61-0.99, N=18$ for each group. Increase in number of workers is probably due to completion of larval development during winter.

ment and the change in the number of workers during the winter (Fig. 1.)

In the laboratory experiment, none of the workers survived from the nests exposed to freezing in approximately $-24{ }^{\circ} \mathrm{C}$. The survival rate of ants in $5{ }^{\circ} \mathrm{C}$ was higher $(45-100 \%, 73.2 \%$ on average) than at $0{ }^{\circ} \mathrm{C}(30-89 \%, 53.2 \%$ on average $)$ (paired-sample Student's $t$ test $t=3.26, d f=8$, $p=0.012$ ).

\section{Discussion}

The number of workers in some Temnothorax crassispinus nests increased during winter in the described field experiment as the final number of workers ranged from $86-120 \%$ of the initial number. This is probably a result of larval development being completed in favourable conditions, as the aboveground temperature in that season periodically remained above $10{ }^{\circ} \mathrm{C}$. As the larvae and eggs present in colonies at the beginning of the experiment were not counted, it was not possible to accurately determine the worker survival rate. In autumn, however, the numbers of larvae in the nests were small (author's own observations) and the colonies could have gained only single new individuals during the winter. The survival rate was therefore undoubtedly high.

Data on the physiological adaptations of ants to overwintering aboveground is scarce. Temnothorax curvispinosus colonies probably neither freeze nor undergo diapause, and it is believed that they are able to withstand low temperatures owing to the production of glycerol or another antifreeze substance (Herbers \& Johnson 2007), which enables them to promptly recommence their activities in favourable temperatures. It may also allow for a rapid resumption of larval development in favourable conditions during the winter months.

The obtained values indicate a high survival 
rate of workers during winter, which is consistent with the data collected during the winter of 2012/13 (see Introduction), but differs from the data provided by the experiment from the 2011/12 season (Mitrus 2013) and the data concerning T. curvispinosus ants (Herbers \& Johnson 2007). A high mortality rate was noted in aboveground nests during the 2011/12 season with a minimum ground-level temperature of $-13.7^{\circ} \mathrm{C}$ (Mitrus 2013), and all individuals died in a freezer in $-24^{\circ} \mathrm{C}$ as a part of the laboratory experiment.

However, high survival rates were observed in the 2012/13 and 2013/14 seasons with minimum temperatures of $-4.8^{\circ} \mathrm{C}$ and $-7.8{ }^{\circ} \mathrm{C}$, respectively. This indicates that low temperatures during winter (and perhaps their long duration) cause considerable mortality in T. crassispinus. The survival may nonetheless also be determined by other factors, such as acclimation (Modlmeier et al. 2012). No correlation was shown in this study between the initial number of workers in a nest and the change in the number of workers over winter, which is consistent with previous results (see Herbers \& Johnson 2007).

Average temperatures are anticipated to rise as a result of climate change, including, and especially, winter temperatures (e.g. Bale \& Hayward 2010, Christensen et al. 2013). The survival rate of $T$. crassispinus was higher in $5^{\circ} \mathrm{C}$ than in $0^{\circ} \mathrm{C}$ during the laboratory experiment. These ants do not accumulate food provisions for winter. The temperature of $5^{\circ} \mathrm{C}$ favoured their overwintering, but there is no data to show whether temperatures higher than this would negatively impact on their survival chances. It is known that winter temperatures higher than typical can contribute to decreased survival rates in other species, e.g. they may cause lower body fat resources and a higher mortality rate in the ant Formica aquilonia (Sorvari et al. 2011).

Besides temperatures, other consequences of climate change should also be expected, such as the reduction in duration of snow cover, a reduced thickness or even a total lack of this cover. The absence/reduced thickness of the snow layer may negatively affect the survival of organisms (Leather et al. 1995, Bale \& Hayward 2010). A thinner and less permanent snow layer may expose overwintering animals to lower tempera- tures and increase the number of periods when animals are subject to alternating plus and minus temperatures (Bradshaw et al. 2004). The survival rate of $T$. crassispinus ants in the present study was surprisingly high; however, the aboveground temperature during the field experiment period never dropped below $-7.8^{\circ} \mathrm{C}$. In such circumstances, the lack of snow cover caused no harmful effects regarding the survival of the studied species, but with no snow cover, even a shortterm low temperature front could lead to substantial mortality among overwintering Temnothorax ants.

Climate change may contribute to both an increase or decrease in the survival of organisms during winter. It may also cause major fluctuations in the survival rate between seasons: the lack of snow cover in higher temperatures may prove critical even during a short cold spell and the freezing of insects overwintering aboveground or just below the surface. Concerning the importance of winter conditions for performance of e.g. insects, it is worth noting that the majority of data on insect life history traits has been collected while insects were active (e.g. Leather et al. 1995, Herbers \& Johnson 2007, Bradshaw \& Holzapfel 2010). Previous research suggested that ants of the genus Temnothorax were subject to strong selection during winter, which might represent a countervailing selection to that occurring in spring and summer (Herbers \& Johnson 2007). Given the fact that Temnothorax ants play a role in seed dispersal (Fokuhl et al. 2012), substantial variations in the survival rate of individuals between seasons (and hence the variable density of colonies) may affect ecosystems.

Survival rate of other invertebrates could also be variable between seasons. The ongoing process of climate change could affect survival rate during winter, and thus the size of populations during the following season (Bale \& Hayward 2010). Unexpected high survival rate of the ant during winter 2013/14 could show expected change in survival rate due to climate change. However, the effects of climate change on the survival of particular invertebrate species may be hard to predict, as, e.g., during mild winters with occasional cold gushes of low temperatures higher mortality should be expected as a consequence of snow cover reduction. 
Acknowledgments. The study was supported by an internal grant (No. 3/KBI/13-S) from the Department of Biosystematics, Opole University. Research in the experimental areas was made possible with the kind permission of the Forest District Offices in Opole and in Olkusz. Two anonymous reviewers provided valuable comments on previous draft of the manuscript.

\section{References}

Bale, J. S. 1996: Insect cold hardiness: A matter of life and death. — European Journal of Entomology 93: 369382.

Bale, J. S. \& Hayward, S. A. L. 2010: Insect overwintering in a changing climate. - Journal of Experimental Biology 213: 980-994.

Bradshaw, W. E. \& Holzapfel, C. M. 2010: Insects at not so low temperature: Climate change in the temperate zone and its biotic consequences: 242-275. - In: Denlinger, D. L. \& Lee, R. E. (eds), Low temperature biology of insects. Cambridge University Press, UK. $406 \mathrm{pp}$.

Bradshaw, W. E., Zani, P. A. \& Holzapfel, C. M. 2004: Adaptation to temperate climates. - Evolution 58: 1748-1762.

Christensen, J. H., Krishna Kumar, K., Aldrian, E., An, S.I., Cavalcanti, I. F. A., de Castro, M., Dong, W., Goswami, P., Hall, A., Kanyanga, J. K., Kitoh, A., Kossin, J., Lau, N.-C., Renwick, J., Stephenson, D. B., Xie, S.P. \& Zhou, T. 2013: Climate Phenomena and their Relevance for Future Regional Climate Change: 12171308. - In: Stocker, T. F., Qin, D., Plattner, G.-K., Tignor, M., Allen, S. K., Boschung, J., Nauels, A., Xia, Y., Bex, V. \& Midgley, P. M. (eds), Climate Change 2013: The Physical Science Basis. Contribution of Working Group I to the Fifth Assessment Report of the Intergovernmental Panel on Climate Change. Cambridge University Press, Cambridge, United Kingdom and New York, NY, USA. 1535 pp.

Czechowski, W., Radchenko, A., Czechowska, W. \& Vepsäläinen, K. 2012: The ants of Poland with reference to the myrmecofauna of Europe. - Museum and Institute of Zoology of the Polish Academy of Sciences and Natura optima dux Foundation, Warszawa, Poland. 496 pp.

Foitzik, S., Strätz, M. \& Heinze, J. 2003: Ecology, life his- tory and resource allocation in the ant, Leptothorax nylanderi. - Journal of Experimental Biology 16: 670680.

Fokuhl, G., Heinze, J. \& Poschlod, P. 2012: Myrmecochory by small ants - Beneficial effects through elaiosome nutrition and seed dispersal. - Acta Oecologica 38: 71-76.

Haatanen, M. K., van Ooik, T. \& Sorvari, J. 2015: Effects of overwintering temperature on the survival of the black garden ant (Lasius niger). - Journal of Thermal Biology 49-50: 112-118.

Heinze, J. \& Buschinger, A. 1988: Polygyny and functional monogyny in Leptothorax ants (Hymenoptera: Formicidae). - Psyche 95: 309-325.

Herbers, J. M. 1989: Community structure in north temperate ants: temporal and spatial variation. - Oecologia 81: 201-211.

Herbers, M. J. \& Johnson, A. C. 2007: Social structure and winter survival in acorn ants. - Oikos 116: 829-835.

Kożuchowski, K. 2011: Klimat Polski. Nowe spojrzenie [Climate of Poland. A new look]. - Wydawnictwo Naukowe PWN, Warszawa, Poland. 293 pp. [In Polish.]

Leather, S. R., Walters, K. F. A. \& Bale, J. S. 1995: The ecology of insect overwintering. - Cambridge University Press, UK. 255 pp.

Lorenc, H. (ed.) 2005: Atlas klimatu Polski [Climate Atlas of Poland]. - Instytut Meteorologii i Gospodarki Wodnej, Warszawa, Poland. 116 pp. [In Polish.]

Mitrus, S. 2013: Cost to the cavity-nest ant Temnothorax crassispinus (Hymenoptera: Formicidae) of overwintering aboveground. - European Journal of Entomology 110: 177-179.

Modlmeier, A. P., Pamminger, T., Foitzik, S. \& Scharf, I. 2012: Cold resistance depends on acclimation and behavioral caste in a temperate ant. - Naturwissenschaften 99: 811-819.

Seifert, B. 2007: Die Ameisen Mittel- und Nordeuropas. — Lutra, Görlitz, Germany. 368 pp.

Sorvari, J., Haatanen, M. K. \& Vesterlund, S. R. 2011: Combined effects of overwintering temperature and habitat degradation on the survival of boreal wood ant. - Journal of Insect Conservation 15: 727-731.

StatSoft, Inc. 2011: STATISTICA (data analysis software system), version 10, www.statsoft.com.

Stearns, S. C. 1992: The Evolution of life histories. - Oxford University Press, Oxford, UK. 264 pp. 